\title{
Nuevo nombre y nueva cita del Cáucaso para una especie de Anachipteria Grandjean, 1932 (Acari, Oribatida, Achipteriidae)
}

\author{
L. S. Subías ${ }^{1}$
}

Como resultado del estudio de los ácaros oribátidos del Caúcaso, ha aparecido una especie, Anachipteria alpina (Schweizer, 1922), recientemente redescrita por Weigmann (2006), perteneciente a la familia Achipteriidae Thor, 1929. Weigmann (l.c.) la considera de distribución europea y propia de los pisos alpinos y subalpinos. Aquí se cita por primera vez del Cáucaso, en muestras recolectadas por la Dra. Umukusum Shtanchaeva en Samur (Dagestán) el día 10 de agosto de 1996, en un bosque subtropical seco compuesto por diversas especies de caducifolios y plantas trepadoras. Se han recolectado 11 ejemplares que se encuentran depositados, parte en el Instituto de Recursos Biológicos del Caspio de Mahachkala (A.C.R.) y parte en la Facultad de Biología de la Universidad Complutense de Madrid. A diferencia de lo comentado anteriormente, donde esta especie aparece a considerable altura en los Alpes, Vosgos y Cárpatos, la nueva localidad se encuentra situada a nivel del mar.

El género Anachipteria Grandjean, 1932, según Subías (2004), es un género de distribución fundamentalmente holártica integrado por 14 especies, de las que solamente una es neotropical. En la última actualización de dicho catálogo realizada por el autor (Subías, 2008) se incluyen 2 especies más, una de ellas dentro del subgénero Anachipteria (Hoffmanacarus) Mahunka, 1995, mientras que otra de las ya descritas amplia su distribución a la Región Oriental; además, se hace notar que $A$. alpina es un homónimo de la especie Oribata alpina Halbert, 1915 -actualmente considerada como sinónimo de Melanozetes stagnatilis (Hull, 1914)- ya que fue descrita como Oribata tecta alpina Schweizer, 1922. En ambas publicaciones (Subías, 2004 y 2008) se considera a esta especie como sinónima de Anachipteria deficiens Grandjean, 1932 siguiendo el criterio de Ber- nini (1974), quien dice textualmente refiriéndose a esta especie: "Cette espèce a été reconnue comme une Anachipteria deficiens par Grandjean (1932)", lo que posiblemente se trate de un error, ya que al consultar la publicación de este autor se comprueba que, al mismo tiempo que describe en nuevo género Anachipteria y designa como especie tipo a la nueva especie $A$. deficiens, menciona que la subespecie descrita por Schweizer debería de ser considerada como buena especie e incluida dentro de este nuevo género. Por lo tanto, A. alpina (Schweizer, 1922) debe de ser considerada como una buena especie, diferente de $A$. deficiens, como hace Weigmann (2006), pero debe de ser renombrada, ya que se trata de un homónimo posterior de O. alpina Halbert, 1915.

Anachipteria (A.) shtanchaevae nom. nov.

(=Oribata tecta alpina Schweizer, 1922, non Halbert, 1915)

ETIMOLOGÍA: Este nuevo nombre está dedicado a la oribatóloga de Dagestán U. Shtanchaeva, especialista en los oribátidos del Caúcaso. De esta manera, queda modificado el catálogo de Subías (2004, 2008).

DISTRIBUCIÓN: Europa centromeridional.

\section{Referencias}

BerninI, F., 1974. Notulae Oribatologicae VIII. Sur le genre Tectoribates Berlese, 1910 (Acarida, Oribatei). Acarologia, 15(3) (1973): 540-554.

GRANDJEAN, F., 1932. Observations sur les Oribates (3e série). Bulletin du Muséum Nationale d'Histoire Naturelle, $2^{\text {ème }}$ série, 4(3): 292-306.

SCHWEIZER, J., 1922. Beiträge zur kenntnis der terrestrischen Milbenfauna der Schweiz. Verhandlungen der Naturforschenden Gesellschaft in Basel, 33: 23-112.

Departamento de Zoología, Facultad de Biología, Universidad Complutense, 28040 Madrid (España).

E-mail: subias@bio.ucm.es 
SuBÍAs, L. S., 2004. Listado sistemático, sinonímico y biogeográfico de los ácaros oribátidos (Acariformes, Oribatida) del mundo (1758-2002). Graellsia, 60(número extraordinario): 3-305.

SuBÍAs, L.S., 2008. Listado sistemático, sinonímico y biogeográfico de los ácaros oribátidos (Acariformes, Oribatida) del mundo (Excepto fósiles). 540 pp. http:// www.ucm.es/info/zoo/Artropodos/Catalogo.pdf Actualización de mayo de 2008.
Weigmann, G., 2006. Hornmilben (Oribatida). Die Tierwelt Deutschlands, 76. Goecke \& Evers. Keltern. $520 \mathrm{pp}$.

Recibido, 27-III-2009

Aceptado, 25-V-2009 Publicado, 29-VI-2009 